\title{
Dentin abrasivity of various desensitizing toothpastes
}

\author{
W. H. Arnold ${ }^{1 *}$, Ch. Gröger ${ }^{1}$, M. Bizhang ${ }^{2}$ and E. A. Naumova ${ }^{1}$
}

\begin{abstract}
Background: The aim of this study was to compare the abrasivity of various commercially available toothpastes that claim to reduce dentin hypersensitivity.

Methods: Dentin discs were prepared from 70 human extracted molars. The discs were etched with lemon juice for 5 min, and one half of the discs were covered with aluminum tape. Following this, they were brushed with 6 different toothpastes, simulating a total brushing time of 6 months. As a negative control, discs were brushed with tap water only. The toothpastes contained pro-arginine and calcium carbonate, strontium acetate, stannous fluoride, zinc carbonate and hydroxyapatite, new silica, or tetrapotassium pyrophosphate and hydroxyapatite. After brushing, the height differences between the control halves and the brushed halves were determined with a profilometer and statistically compared using a Mann-Whitney $U$ test for independent variables.
\end{abstract}

Results: A significant difference $(p<0.001)$ in height difference between the controls and the toothpaste-treated samples was found in all cases, except for the stannous fluoride-containing toothpaste $(p=0.583)$. The highest abrasion was found in the toothpaste containing zinc carbonate and hydroxyapatite, and the lowest was found in the toothpaste containing pro-arginine and calcium carbonate.

Conclusions: Desensitizing toothpastes with different desensitizing ingredients have different levels of abrasivity, which may have a negative effect on their desensitizing abilities over a long period of time.

Keywords: Toothpaste, Dentin, Dentin tubules, Root dentin, Hypersensitivity

\section{Background}

The prevalence of dentin hypersensitivity has been increasing over the past decades [1], and there is a need for adequate treatment of this condition. The causes of dentin hypersensitivity include open dentin tubules due to gingival recession and subsequent cervical dentin erosion [2]. Dentin erosion occurs for a variety of reasons. Amongst them are erosive foods and beverages, as well as esophageal reflux or eating disorders [3]. Another reason for dentin erosion may be the use of toothpastes and toothbrushes [4]. Various strategies have been developed to handle this problem. They range from home-use dental products, such as desensitizing toothpastes [5-10], to inoffice treatments, such as sealing dentin tubules either with a varnish [11-13] or with a dentin adhesive [14, 15]. The

\footnotetext{
* Correspondence: wolfgang.arnold@uni-wh.de

${ }^{1}$ Department of Biological and Material Sciences in Dentistry, School of

Dentistry, Witten/Herdecke University, Witten, Germany

Full list of author information is available at the end of the article
}

first choice treatment of dentin hypersensitivity is homeuse dental products, mainly desensitizing toothpastes.

Desensitizing toothpastes are divided into two groups with different mechanisms of action. The first group comprises toothpastes that block pulp nerve responses, whereas the second group comprises toothpastes that occlude dentin tubules [16]. All desensitizing toothpastes have different ingredients, which have different effects on the ability to occlude dentin tubules [5]. All of these toothpastes are similar in that they have certain levels of abrasivity within a relative-dentin-abrasion (RDA) value range between 20 and 120. In a recent study, it was shown that toothpastes with high RDA values resulted in greater losses of dentin [4] after tooth brushing. The abrasivity of desensitizing toothpastes may have an adverse effect on the occlusion of dentin tubules because the tubules might be reopened during the brushing procedure.

Therefore, the aim of this study was to compare the abrasivity of various desensitizing toothpastes quantitatively. 
The null hypothesis stated that there is no difference in the abrasivity of the different included toothpastes.

\section{Methods}

Seventy caries-free extracted human molars were used for this experimental study. The collection of the teeth was approved by the ethical committee of Witten/Herdecke University (116/2013). Informed verbal consent was obtained from the patients before the use of their teeth. The teeth were stored in $0.9 \% \mathrm{NaCl}$ containing $0.1 \%$ thymol until use.

\section{Experimental design}

From the 70 teeth, 3-mm-thick dentin discs were prepared using a saw microtome (Leica 1600, Leitz Wetzlar, Germany). The discs were randomly divided into 7 groups of 10 discs each and etched with lemon juice (Hitchcock, Mönchen Gladbach, Germany) for $5 \mathrm{~min}$, and one half of each disc were covered with aluminum tape. Following this, the discs were placed into a tooth-brushing machine, and a tooth brushing time of 6 months was simulated. The brushing time was calculated as follows: 28 teeth per oral cavity assuming a vestibular and an oral surface $=56$ surfaces. A recommended brushing time of $360 \mathrm{~s}$ per day results in a brushing time of $6.4 \mathrm{~s}$ per tooth surface. This is multiplied by 182.5 days (6 months) and results in a total brushing time per tooth surface of $19 \mathrm{~min} 33 \mathrm{~s}$. The used toothbrush has an active brushing field of $28 \mathrm{~mm}$ length which would cover two tooth surfaces at one time in the oral cavity, therefore, the brushing time was again doubled and resulted in a total bushing time per surface of $39 \mathrm{~min}$ and $6 \mathrm{~s}$. As toothbrush the American Dental Association Standard Toothbrush was used. The toothbrush load was $2 \mathrm{~N}$. The standard toothbrush of the American Dental Association was used with 120 linear strokes per min. The toothpastes and the active ingredients that were used are summarized in Table 1. One group served as a negative control and was brushed with tap water only. After tooth brushing, the aluminum tape was removed, and the height differences between the covered halves and the brushed halves of the discs were determined using an optical profilometer (Infinite focus G3,
Alicona, Germany). Twenty measurements per disc were made, and the mean value was calculated for each disc.

\section{Statistical analysis}

Sample size calculation was carried out (Axum 7, Mathsoft, Cambridge, Massachusetts, USA) with data obtained in a preliminary experiment with a power of 0.8 and a significance level of $\alpha<0.05$, revealing a minimum number of 8 specimens per group. The mean values of the height differences were compared between the different toothpastes and the negative controls using a Wilcoxon-Mann-Whitney test for independent variables and post hoc Bonferroni adjustment, which resulted in a final $\mathrm{p}$ value of 0.0083 . The correlation between abrasivity and RDA value was calculated with the nonparametric Spearman-Rho test. Descriptive statistics are presented as boxplots. All calculations were performed with SPSS (IBM Corporation, Armonk, NY, USA; Rel. 21) statistical software.

\section{Results}

The statistical evaluation showed significant differences $(p<0.001)$ between the negative control and toothpastes 1-5 (Fig. 1). The difference between toothpaste 6 with tetrapotassium pyrophosphate, hydroxyapatite and the negative control was not significant $(p=0.583)$. The exact descriptive data are summarized in Table 2. The highest abrasion was found in the toothpaste containing zinc carbonate and hydroxyapatite carbonate (toothpaste $\# 1)$. A significant correlation $(p<0.001)$ between the height difference on the dentin discs and RDA value with a correlation coefficient of $r=0.568$ was found. The graphic representation demonstrated a rather mild correlation (Fig. 2)

\section{Discussion}

Erosion of the tooth surface in the cervical area results in a loss of covering cementum and an opening of dentin tubules, which in turn leads to dentin hypersensitivity. The use of desensitizing toothpastes is always the first recommendation for the treatment of dentin hypersensitivity [6]. The mechanism of action of the majority of desensitizing toothpastes is an effect on dentin tubule occlusion $[5,16]$. The cleaning effect of toothpastes is due to their RDA values and other abrasive components

Table 1 Summary of toothpastes used

\begin{tabular}{|c|c|c|c|}
\hline Product name & Active ingredient & RDA value ${ }^{a}$ & Company \\
\hline BioRepair (\#1) & Zinc carbonate hydroxyapatite & 69 & Dr. K. Wolff, Bielefeld, Germany \\
\hline Elmex Sensitive Professional (\#2) & Pro-arginine, calcium carbonate & 30 & CP-GABA, Hamburg, Germany \\
\hline Elmex (\#3) & Amine fluoride & 77 & CP-GABA, Hamburg, Germany \\
\hline Sensodyne Rapid (\#4) & Strontium acetate & 70 & GlaxoSmithKline, Brentford, UK \\
\hline Sensodyne Repair (\#5) & Stannous fluoride & 119 & GlaxoSmithKline, Brentford, UK \\
\hline Dontodent Sensitive (\#6) & Tetrapotassium pyrophosphate, hydroxyapatite & 20 & DM Dogeriemarkt, Karlsruhe, Germany \\
\hline
\end{tabular}




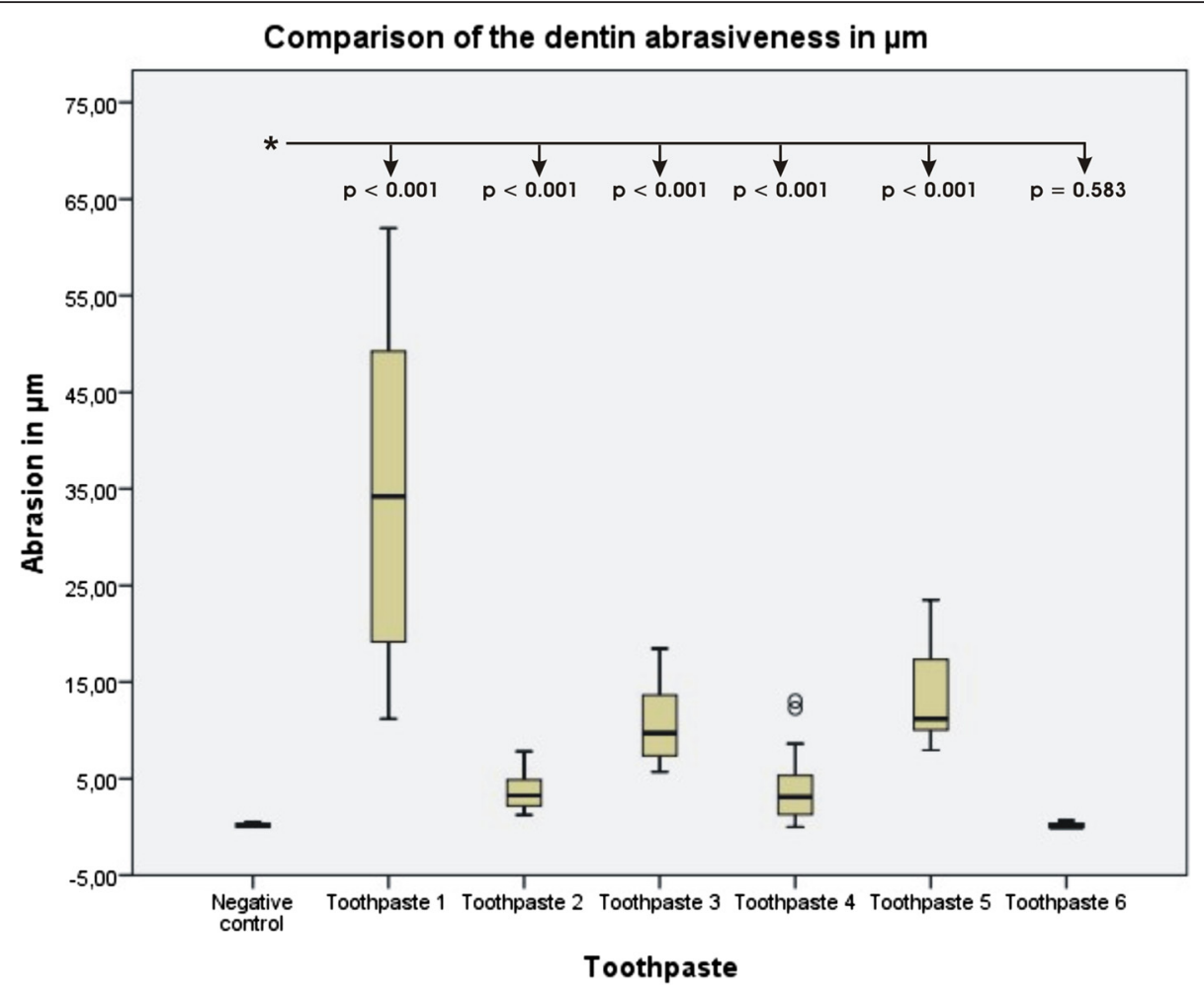

Fig. 1 Boxplot graphics showing data distribution of abrasion values in $\mu \mathrm{m}$. The box is representing $50 \%$ of the measured values, whiskers the $75 \%$ percentile and circles extremes, the box within the box marks the median

such as nanoparticles. A high RDA value results in a large amount of dentin abrasion, which then might reopen occluded tubules and diminish the sensitizing effect.

The results of this study demonstrated large differences in the abrasivity of the various investigated desensitizing toothpastes. The abrasivity of toothpaste is dependent on numerous factors. The main factor is the content of abrasives [17]. All toothpastes used in this study employed silica as an abrasive substance. However, other ingredients, such as $\mathrm{CaCO}_{3}$, hydroxyapatite, and other nanoparticles, may also contribute to the abrasivity of toothpaste [17]. All toothpastes contain a variety of different ingredients, which makes it almost impossible to determine the influence of a certain substance on the abrasivity of

Table 2 Descriptive data of abrasion values

\begin{tabular}{lcccc}
\hline Toothpaste \# & Median & Minimum & Maximum & Interquartile range \\
\hline 1 & 34.20 & 11.22 & 61.98 & 50.76 \\
2 & 32.66 & 1.25 & 7.84 & 6.59 \\
3 & 9.73 & 5.72 & 18.47 & 12.75 \\
4 & 3.11 & 0.00 & 13.04 & 13.04 \\
5 & 11.21 & 7.96 & 23.52 & 15.55 \\
6 & 0.00 & 0.00 & 0.67 & 0.67 \\
tape water & 0.02 & 0.00 & 0.49 & 0.49
\end{tabular}

All values are in $\mu \mathrm{m}$ a toothpaste. This is emphasized by the results of this investigation. Especially toothpaste 6 demonstrated no abrasiveness compared to water but does contain tetrapotassium pyrophosphate, hydroxyapatite as active ingredient. It remains speculative weather the hydroxyapatite particles are too small for being abrasive. The influence of the RDA on the loss of hard dental tissue has been discussed widely in the literature [4,17-20]. In this study, a correlation between RDA value and amount of dentin loss was also found. Although the correlation was significant $(p<0.001)$, the correlation coefficient was not very strong $(r=0.568)$, and the graphic representation did not show a clear linear correlation between increasing RDA value and amount of substance loss. This finding is in accordance with the results of another study, which did not find a correlation between RDA value and dentin abrasivity [21]. The reason for this mild correlation might be the relatively low number of investigated specimens.

There is still an ongoing debate as to whether toothpastes are contributing to dentine hypersensitivity [18, 22]. Desensitizing toothpastes should remove the smear layer on dentin and leave deposits of particles, which occlude dentin tubules $[2,23]$. Another study showed that desensitizing toothpastes partly occlude dentin tubules [5], but the abrasivity of toothpastes was not investigated. In this study, it could be shown that under experimental conditions and 


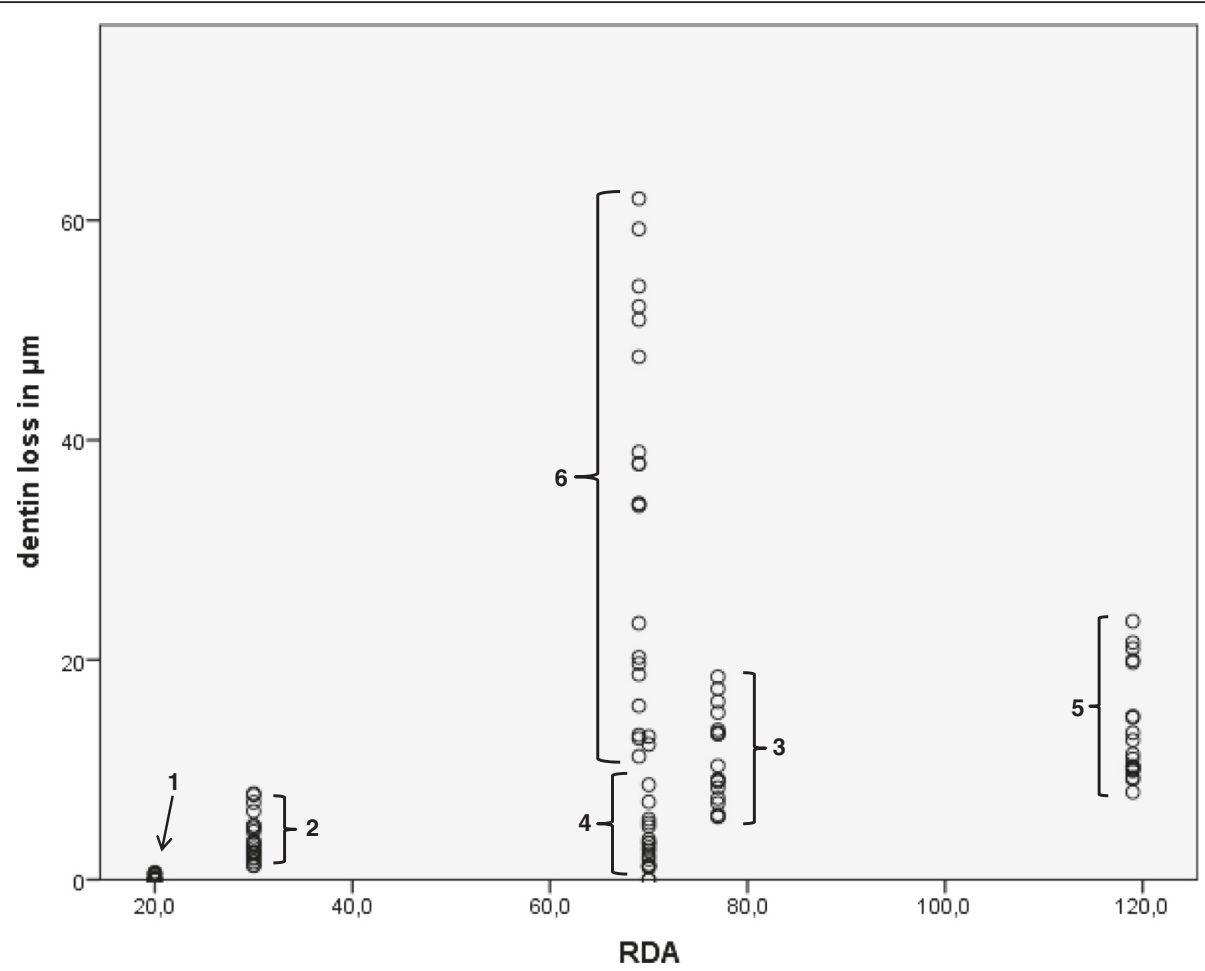

Fig. 2 Correlation between dentin loss and RDA value of toothpaste. The numbers are representing the toothpaste numbers

after dentin erosion a maximum of $61.98 \mu \mathrm{m}$ dentin was removed. Therefore, it is very likely that dentine tubules were not occluded in these cases.

\section{Conclusions}

Within the limitations of an in vitro study, it can be concluded that different desensitizing toothpastes have different abrasivity regardless of their content of active desensitizing ingredients. Abrasivity of toothpastes may hamper their desensitizing effects.

\section{Competing interests}

The authors declare that they have no competing interests.

\section{Author contributions}

WHA: wrote the manuscript, calculated the statistics. CG: conduced the experiments. MB: planning the experiments, clinical advice. EAN: responsible for final correction of the manuscript, supervising the project. All authors read and approved the final manuscript.

\section{Acknowledgements}

The authors would like to thank Mrs. Susanne Haussman for her technical assistance in preparing the dentin discs and Mr. Christin Greune for assistance with the brushing machine.

CP-GABA, Hamburg provided the Elmex toothpastes.

\section{Author details}

${ }^{1}$ Department of Biological and Material Sciences in Dentistry, School of Dentistry, Witten/Herdecke University, Witten, Germany. ${ }^{2}$ Department of Preventive and Operative Dentistry, School of Dentistry, Witten/Herdecke University, Witten, Germany.

Received: 11 December 2015 Accepted: 30 March 2016 Published online: 02 April 2016

\section{References}

1. Cummins D. Dentin hypersensitivity: from diagnosis to a breakthrough therapy for everyday sensitivity relief. The Journal of clinical dentistry. 2009:20(1):1-9.

2. West NX. Dentine hypersensitivity. Monographs in oral science. 2006;20: 173-89. doi:10.1159/000093362.

3. Milosevic A, Bardsley PF, Taylor S. Epidemiological studies of tooth wear and dental erosion in 14-year old children in North West England. Part 2: The association of diet and habits. Br Dent J. 2004;197(8):479-83. doi:10.1038/sj. bdj.4811747. discussion 3; quiz 505.

4. Bizhang M, Riemer K, Arnold, WH, Domin J, Zimmer, S. Influence of Bristle Stiffness of Manual Toothbrushes on Eroded and Sound Human Dentin - an In Vitro Study. Plos ONE (in press).

5. Arnold $W H$, Prange $M$, Naumova EA. Effectiveness of various toothpastes on dentine tubule occlusion. J Dent. 2015:43(4):440-9. doi:10.1016/j.jdent.2015.01.014.

6. Canadian Advisory Board. Consensus-based recommendations for the diagnosis and management of dentin hypersensitivity. J Can Dent Assoc. 2003;69(4):221-6.

7. Cummins D. Advances in the clinical management of dentin hypersensitivity: a review of recent evidence for the efficacy of dentifrices in providing instant and lasting relief. The Journal of clinical dentistry. 2011; 22(4):100-7.

8. Gillam DG, Newman HN, Davies EH, Bulman JS. Clinical efficacy of a low abrasive dentifrice for the relief of cervical dentinal hypersensitivity. Journal of clinical periodontology. 1992:19(3):197-201.

9. Markowitz K, Pashley DH. Discovering new treatments for sensitive teeth: the long path from biology to therapy. Journal of oral rehabilitation. 2008; 35(4):300-15. doi:10.1111/j.1365-2842.2007.01798.x.

10. Petrou I, Heu R, Stranick M, Lavender S, Zaidel L, Cummins D, et al. A breakthrough therapy for dentin hypersensitivity: how dental products containing $8 \%$ arginine and calcium carbonate work to deliver effective relief of sensitive teeth. The Journal of clinical dentistry. 2009:20(1):23-31.

11. Baysan A, Lynch E. Treatment of cervical sensitivity with a root sealant. American journal of dentistry. 2003;16(2):135-8.

12. Duran I, Sengun A. The long-term effectiveness of five current desensitizing products on cervical dentine sensitivity. Journal of oral rehabilitation. 2004: 31(4):351-6. doi:10.1046/j.1365-2842.2003.01241.x. 
13. Kielbassa AM, Attin T, Hellwig E, Schade-Brittinger C. In vivo study on the effectiveness of a lacquer containing $\mathrm{CaF} 2 / \mathrm{NaF}$ in treating dentine hypersensitivity. Clinical oral investigations. 1997;1(2):95-9.

14. Panduric V, Knezevic A, Tarle Z, Sutalo J. The efficiency of dentine adhesives in treating non-caries cervical lesions. Journal of oral rehabilitation. 2001; 28(12):1168-74.

15. Trowbridge HO, Silver DR. A review of current approaches to in-office management of tooth hypersensitivity. Dental clinics of North America. 1990;34(3):561-81.

16. Addy M, West NX. The role of toothpaste in the aetiology and treatment of dentine hypersensitivity. Monographs in oral science. 2013;23:75-87. doi:10. 1159/000350477.

17. Moore C, Addy M. Wear of dentine in vitro by toothpaste abrasives and detergents alone and combined. Journal of clinical periodontology. 2005; 32(12):1242-6. doi:10.1111/j.1600-051X.2005.00857.X.

18. Addy M. Tooth brushing, tooth wear and dentine hypersensitivity-are they associated? International dental journal. 2005;55(4 Suppl 1):261-7.

19. Addy M, Hughes J, Pickles MJ, Joiner A, Huntington E. Development of a method in situ to study toothpaste abrasion of dentine. Comparison of 2 products. Journal of clinical periodontology. 2002;29(10):896-900.

20. Turssi CP, Messias DC, de Menezes M, Hara AT, Serra MC. Role of dentifrices on abrasion of enamel exposed to an acidic drink. American journal of dentistry. 2005;18(4):251-5.

21. Aykut-Yetkiner A, Attin T, Wiegand A. Prevention of dentine erosion by brushing with anti-erosive toothpastes. Journal of dentistry. 2014. doi:10. 1016/j.jdent.2014.03.011.

22. West N, Addy M, Hughes J. Dentine hypersensitivity: the effects of brushing desensitizing toothpastes, their solid and liquid phases, and detergents on dentine and acrylic: studies in vitro. Journal of oral rehabilitation. 1998; 25(12):885-95.

23. West NX, Addy M, Jackson RJ, Ridge DB. Dentine hypersensitivity and the placebo response. A comparison of the effect of strontium acetate, potassium nitrate and fluoride toothpastes. Journal of clinical periodontology. 1997;24(4):209-15.

\section{Submit your next manuscript to BioMed Central and we will help you at every step:}

- We accept pre-submission inquiries

- Our selector tool helps you to find the most relevant journal

- We provide round the clock customer support

- Convenient online submission

- Thorough peer review

- Inclusion in PubMed and all major indexing services

- Maximum visibility for your research

Submit your manuscript at www.biomedcentral.com/submit

C Biomed Central 